\title{
THE POTENCY OF ANGLE MEASUREMENT AND COMPARISON OF VEIN LENGTHS IN DISTINGUISHING BACTROCERA SPECIES COMPLEXES
}

\author{
Gesang Pratyadhiraksana ${ }^{1}$, Tri Murniningtyas Puji Lestari ${ }^{2}$, Rudi Hari Murti ${ }^{3}$ \& Suputa $^{3}$ \\ ${ }^{1}$ Master Program of Plant Pests Science, Faculty of Agriculture, Universitas Gadjah Mada, Indonesia \\ Jl. Flora Bulaksumur Sleman Yogyakarta 55281 \\ ${ }^{2}$ Pest Forecasting Institute, Indonesia \\ Jl. Raya Kaliasin Tromol Pos 1 Jatisari Karawang 41374 \\ ${ }^{3}$ Faculty of Agriculture, Universitas Gadjah Mada, Indonesia \\ Jl. Flora Bulaksumur Sleman Yogyakarta 55281 \\ E-mail: gesang.21293@gmail.com
}

Manuscript received: 22 April 2020. Revision accepted: 9 May 2020

\begin{abstract}
The potency of angle measurement and comparison of vein lengths in distinguishing Bactrocera species complexes. One of the most conspicuous features of Bactrocera fruit flies is their wing, which can be elaborated for identification. The distinctive wing patterns are used to separate species and classify species complexes. The wing shape can be used as a potential discriminator between closely related taxa. To develop wing applications in taxonomy, in this study, the degree measure of angles and the comparisons of vein lengths were investigated quantitatively to distinguish among important pest quarantine species of the Bactrocera dorsalis complex: $B$. dorsalis and B. carambolae; the $B$. frauenfeldi complex: $B$. frauenfeldi and B. albistrigata; and a species belonging to subgenus Zeugodacus, B. cucurbitae. The result showed that species complexes were clustered into significantly different groups based on the degree measure of cell br and the comparison between $\mathrm{r}-\mathrm{m}$ and $\mathrm{dm}-\mathrm{cu}$ cross-vein length. This conclusive evidence was supported by phylogenetic analysis using COI gene. This present result indicated that the cell br angle measure and the comparison between $\mathrm{r}-\mathrm{m}$ and $\mathrm{dm}$-cu vein length could be applied to distinguish species complexes in genus Bactrocera.
\end{abstract}

Key words: cryptic species, insect wing, morphometric, vein ratio, venation angle

\section{INTRODUCTION}

Within the family Tephritidae, the true fruit fly, the genus Bactrocera is the largest genera with over 500 species (Drew \& Romig, 2013). Certain Bactrocera species are known to be most notorious agricultural pests that cause heavy losses in fruit and vegetable crops in tropical and subtropical Asia, Australia, and Pacific Islands. Fruit fly management usually has the problem in morphological identification of several taxa, especially within a species complex due to shared morphological characters. In addition, although distinctive traits have been described by Drew (1989), occurrence of colour polymorphism arose in distinguishing closely related species (Leblanc et al., 2013).

The reliable methods are necessary to distinguish cryptic taxa belonging to species complexes. There are various studies that has been applied independently to answer biological relationship among closely related species, such as molecular genetics (Nakahara \& Muraji, 2008; Boykin et al., 2014), sexual compatibility (Schutze et al., 2013), and chemoecology (Wee \& Tan, 2005; Tan et al., 2011). Molecular phylogenetic analysis has better resolving power due to its rapid and precise result. The barcode region of the COI gene (mitochondrial cytochrome c oxidase I gene) is reliable molecular marker that has been intensively used in taxonomic classification and identification among closely related Bactrocera species (Clarke, 2019).

Morphometrics have been become alternative taxonomic method for quantitative descriptions in biology (Mitteroecker et al., 2013). Based on its development, morphometric divided into two methods. First method called traditional morphometric was done by measuring linear distances, such as length, width, and height. In Bactrocera fruit fly, morphometric approach based on male aedeagal length were studied as a discriminator of morphologically similar pest taxa within the $B$. dorsalis complex (Iwahashi, 1999a; Iwahashi, 1999b). However, these approaches showed substantial intraspecific variation and overlap data (Iwahashi, 2001). Krosch et al. (2013) reported that genitalia length of fruit flies 
correlated with latitude which fruit flies in northern Asia had shorter aedeagi than fruit flies in southern Asia. Further, despite genitalia length, the measurements of wing vein characters of Bactrocera were investigated by Adsavakulchai et al. (1999) but it could not be categorized properly.

To overcome the weakness of traditional morphometric, the second method called geometric morphometrics was created. Geometric morphometrics have also been applied in detecting quantitatively morphological differences in order to assist identification. This technique is sensitively useful for visualizing dissimilar geometrical shapes from every single small distinction (Zaelor \& Khittawee, 2018). According to Schutze et al. (2012), wing shape has a high degree of accuracy to discriminate fruit fly species. Wing shape has been applied to distinguish morphologically similar pest taxa within the $B$. dorsalis complex (Khamis et al., 2012; Schutze et al., 2012), B. tau complex (Kitthawee \& Dujardin, 2010; Kitthawee \& Rungsri, 2011; Zaelor \& Khittawee, 2018). Anastrepha fraterculus complex (Perre et al., 2014), and Blepharoneura spp. (Marsteller et al., 2009).

As wing shape successes in discriminating among the morphologically cryptic species, it rises assumption that the angle measures and comparison between two vein lengths tend to be consistent. Furthermore, the ratios and angle measures are not correlated with size that makes quantitative descriptions difficult (Mitteroecker $\&$ Gunz, 2009). The analysis of degree angle and ratio resulting from comparison between two vein lengths was expected to explain dissimilar geometrical shapes presented by geometric morphometric analysis. Perhaps, these approaches sensitive enough in clustering at least species complexes. Therefore, the aim of this present study was to use angle measures and comparison between two vein lengths to distinguish previously identified specimens of $B$. dorsalis, $B$. carambolae (the $B$. dorsalis complex), B. frauenfeldi, $B$. albistrigata (the $B$. frauenfeldi complex), and $B$. cucurbitae. Subsequently, these approaches will be compared with molecular genetic to see their consistency. If vein ratios and degree angles accurately reflected the species or species complex groupings as phylogenetic analysis using COI gene, these approaches could be a potential discriminator in certain taxonomy level.

\section{MATERIALS AND METHODS}

Research Site. The B. frauenfeldi samples were obtained by field trapping using cue lure trap from various locations in Sorong City, West Papua for a month, in August 2019. Individuals B. carambolae, B. dorsalis, $B$. albistrigata, and $B$. cucurbitae were obtained from Pest Forecasting Institute, Karawang, Indonesia. Wild and mass reared samples were preserved and transported to the Entomology Laboratory at Universitas Gadjah Mada, Yogyakarta, Indonesia for further analysis. This study was conducted from August to October 2019.

Morphometric. The 100 male wings from each species were dissected for the measurement of their veins. The right wing dissected was mounted on a microscope slide and covered with a glass coverslip. The slides were photographed with stereomicroscope Olympus SZ61 and saved in JPEG format. For analysis, six measurements of the veins and angles were taken using TpsDig2 V2.32 software (Figure 1). These measurements were used to calculate comparison of vein lengths for each individual. The comparisons were

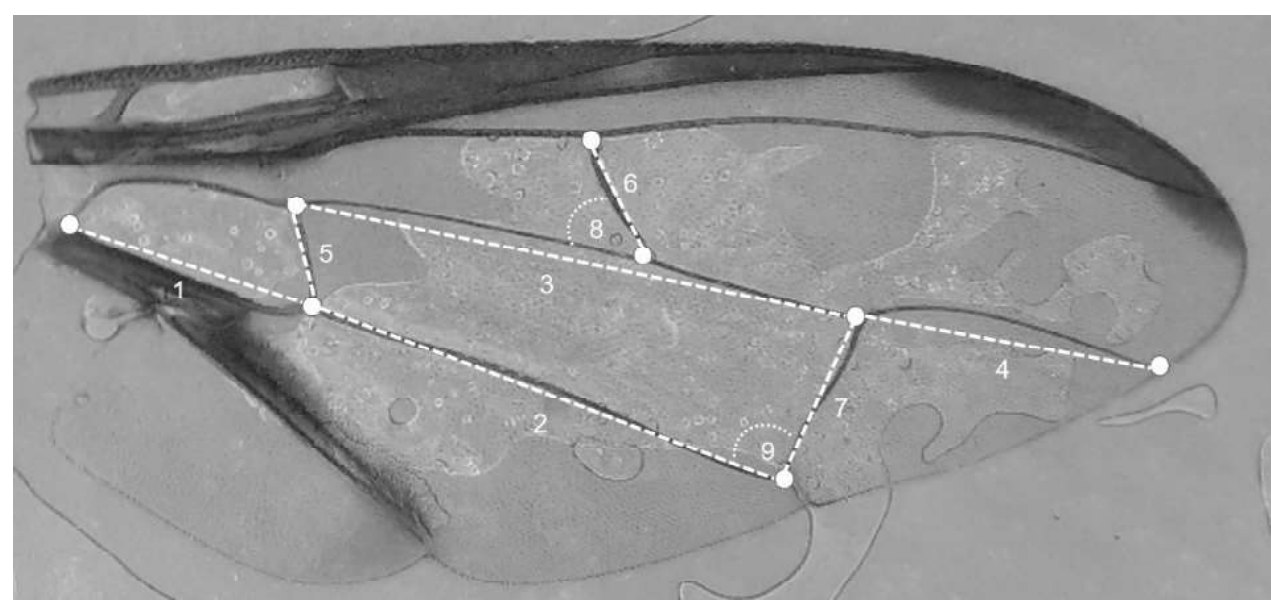

Figure 1. The measurements in wing venation. (1) Bm vein; (2) CuA vein; (3) Dm vein; (4) M vein; (5) bm-cu cross-vein; (6) dm-cu cross-vein; (7) r-m cross-vein; (8) angle of cell br; and (9) angle of cell dm. 
as follows: (1) vein bm : $\mathrm{CuA}_{1}$ vein; (2) vein $\mathrm{Dm}: \mathrm{CuA}$ vein; (3) Dm vein : M vein; (4) bm-cu cross-vein : dmcu cross-vein; and (5) r-m cross-vein: dm-cu cross-vein. The size of venation cell angle of cell br and $\mathrm{dm}$ were also calculated (Figure 1). The all data were checked for normality by using the Kolmogorov-Smirnov test. Subsequently, data were analyzed using one-way analysis of variance to compare data from each species. The Tukey post hoc test was used to compare the means $(\mathrm{P}<0.05)$. All statistical analyses were performed in SPSS. 23.

Molecular Analysis. DNA isolation of imago was based on the CTAB (cetyl-trimethyl-ammoniumbromide) protocol described by Doyle \& Doyle (1990) with several modification. Each fruit fly thorax was ground in $500 \mu \mathrm{L}$ of $60{ }^{\circ} \mathrm{C}$ CTAB buffer $(2 \%$ CTAB, $1.4 \mathrm{M} \mathrm{NaCl}, 100 \mathrm{mM}$ Tris-HCl, $20 \mathrm{mM}$ EDTA, and $0.2 \% \beta$-mercaptoethanol) using sterile micro pestle in a $1.5 \mathrm{~mL}$ centrifuge tube. The suspension was vortexed and incubated for $45 \mathrm{~min}$ at $65^{\circ} \mathrm{C}$ with intermittent mixing. The sample was centrifuged for $10 \mathrm{~min}$ at $10,000 \mathrm{rpm}$ at $4{ }^{\circ} \mathrm{C}$. The supernatant was transferred into $1.5 \mathrm{~mL}$ centrifuge tube and equal volume of phenolchloroform-isoamyl alcohol (25:24:1) was added and repeatedly inverted. The suspension was centrifuged for $10 \mathrm{~min}$ at $10,000 \mathrm{rpm}$ at $4{ }^{\circ} \mathrm{C}$ and the supernatant was transferred into $1.5 \mathrm{~mL}$ centrifuge tube. The DNA was precipitated by adding an equal volume of absolute ethanol $\left(-20^{\circ} \mathrm{C}\right)$ and mixing it. The suspension was incubated for overnight at $-20{ }^{\circ} \mathrm{C}$ and then DNA was pelleted by centrifugation for $20 \mathrm{~min}$ at $12,000 \mathrm{rpm}$ at $4{ }^{\circ} \mathrm{C}$. The supernatant was removed and $70 \%$ alcohol was added to wash pellet. Subsequently, the suspension was centrifuged for $5 \mathrm{~min}$ at 4,000 rpm then alcohol was discarded. Finally, the pellet was air-dried in silica gel and re-suspended in $40 \mu \mathrm{L}$ nuclease-free water.

A mitochondrial DNA, Cytochrome Oxidase subunit I (COI), was analysed. PCR was conducted using universal primers reported by Folmer et al. (1994) (Table 1). DNA amplification in PCR method was carried out in a $30 \mathrm{~mL}$ volume containing $15 \mu \mathrm{L}$ taq DNA polymerase (Bioline), $3 \mu \mathrm{L}$ DNA template, $3 \mu \mathrm{L}$ forward primer, $3 \mu \mathrm{L}$ reverse primer, and $12 \mu \mathrm{L} \mathrm{ddH_{2 }}$ O. PCR cycling conditions consisted of an initial denaturation step at $94{ }^{\circ} \mathrm{C}$ for $2 \mathrm{~min}$, followed by 35 cycles of denaturation at $94{ }^{\circ} \mathrm{C}$ for $30 \mathrm{~s}$, annealing at $48{ }^{\circ} \mathrm{C}$ for $30 \mathrm{~s}$ and extension at $72{ }^{\circ} \mathrm{C}$ for $1 \mathrm{~min}$. There was a final run-out extension step at $72{ }^{\circ} \mathrm{C}$ for $7 \mathrm{~min}$. The $3 \mu \mathrm{L}$ of samples from PCR products and 1000 bp marker were run in $1.5 \%$ of agarose gel to determine the existence and size of amplified DNA.

The Qualified PCR product was then sequenced to determine the nucleotide sequence in cytochrome oxidase I region. The products were sent to the Integrated Research and Testing Laboratory, Gadjah Mada University. The forward and reverse sequences obtained were assembled and edited manually using BioEdit v. 7.0.9 (Hall, 1999), and then analyzed using BLAST (Basic Local Alignment Search Tool) NCBI (https://blast.ncbi.nlm.nih.gov/Blast.cgi) to clarify the homology from closest species. The Maximum-likelihood tree were constructed using MEGA (Molecular Evolutionary Genetics Analysis) software version X (Kumar et al., 2018).

\section{RESULTS AND DISCUSSION}

Vein Lengths. The male wings from all species (100 right wing/species) were dissected for the vein measurement. The vein lengths resulting among the five species studied were significantly varied in seven vein measurements $(\mathrm{P}=0.001)$ (Table 2$)$. Overall, the shortest vein length was recorded on $B$. albistrigata and was followed by $B$. frauenfeldi. On the other hand, $B$. cucurbitae had longest vein lengths, except on $M$ vein. The measurements clearly demonstrated that the vein lengths highly correlated with wing size. However, the result of vein lengths could not separate the five species studied according to species complexes because it showed ranges of overlap. Adsavakulchai et al. (1999) reported that vein lengths were correlated with the wing size which made identification difficult. In addition, Schutze et al. (2012) also discovered that vein length and wing size could not effectively discriminate one species from the other due to there was no consistent significant difference in wing size of Bactrocera fruit flies from various countries.

The adult size variation can clearly be determined by variation in the growth rate and the duration of developmental time during the last larval instar (Chown $\&$ Gaston, 2010). The quality and amount of larval food

Table 1. Primer mtDNA Cytochrome Oxidase subunit I (Folmer et al., 1994)

\begin{tabular}{cc}
\hline Primer name & Sequence \\
\hline LCO1490 (Forward Primer) & 5'-GGTCAACAAATCATAAAGATATTGG-3' \\
HCO2198 (Reverse Primer) & 3'-TAAACTTCAGGGTGACCAAAAAATCA-5' \\
\hline
\end{tabular}


source affect larval growth rate, which in turn determines larval and adult size (Davidowitz \& Nijhout, 2004). The different host plants influenced wing size of $B$. dorsalis, Ceratitis capitata (Pieterse et al., 2017), Drosophila gouveai and D. antonietae (Soto et al., 2010). The nutritional approach studied by Sentinella et al. (2013) revealed that the increasing body size of Telostylinus angusticollis (Diptera: Neriidae) was affected by carbohydrate in larval diet. In addition, the high temperature has an impact on biochemical reactions which triggers moulting, therefore the developmental time become shorter. Total larval duration of $B$. dorsalis and $B$. carambolae declined exponentially at $30-35^{\circ} \mathrm{C}$ (Danjuma et al., 2014). Moreover, condition experienced during the immature stage may affect adult size as Benitez et al. (2013) found that the hind wing size of Diabrotica virgifera (Coleoptera: Chrysomelidae) changed according to the major types of soil.

The Angle Measurements and Comparison of Vein Lengths. Two cell angles (cell br and $\mathrm{dm}$ ) were measured for each species. The degree angles of five fruit flies studied were statistically different for cell br $(\mathrm{P}=0.0001)$ and cell $\mathrm{dm}(\mathrm{P}=0.0001)$. However, the potential discriminator among Bactrocera species complexes was showed in the angle measurement of cell br (Table 3). The Tukey post hoc test revealed that degree angle of cell br among species complexes was significantly different. The $B$. frauenfeld $i$ complex samples had the significantly smallest degree angle of cell ber and was followed by $B$. dorsalis complex and $B$. cucurbitae, with the angle measure respectively, $33.27^{\circ}-44.65^{\circ} ; 50.82^{\circ}-65.10^{\circ}$; and $65.05^{\circ}-74.35^{\circ}$. The obtained result explained quantitively differences found directly on the wing venation pattern among five species studied, especially in cell br shape (Figure 2). Further, degree angle of cell br had a role in distinguishing among species complexes based on comparison between vein $\mathrm{r}-\mathrm{m}$ and $\mathrm{dm}-\mathrm{cu}$ because it is related to length of dm-cu cross-vein. The ratios resulting from comparison between vein $r-m$ and $d m-c u$ significantly varied among five species studied ( $\mathrm{P}=0.0001$ ) (Table 3 ). Subsequently, the Tukey post hoc test showed that ratios were divided into three groups, namely $B$. frauenfeld $i$ complex (0.79-0.96), B. dorsalis complex (0.65-0.81), and $B$. cucurbitae (0.56-0.68). On the other hand, comparison of other vein lengths did not separate species complexes.

Our results showed that degree angle of cell br and comparison between vein $\mathrm{r}-\mathrm{m}$ and $\mathrm{dm}$-cu explained

Table 2. The length of wing vein (mm) in different species Bactrocera spp.

\begin{tabular}{lccccc}
\hline Vein & B. frauenfeldi & B. albistrigata & B. dorsalis & B. carambolae & B. cucurbitae \\
\hline Bm & $0.92 \pm 0.08 \mathrm{~b}$ & $0.78 \pm 0.05 \mathrm{a}$ & $0.94 \pm 0.04 \mathrm{c}$ & $0.94 \pm 0.06 \mathrm{c}$ & $1.14 \pm 0.05 \mathrm{~d}$ \\
CuA1 & $1.52 \pm 0.07 \mathrm{~b}$ & $1.36 \pm 0.07 \mathrm{a}$ & $1.86 \pm 0.09 \mathrm{c}$ & $1.84 \pm 0.10 \mathrm{c}$ & $2.05 \pm 0.08 \mathrm{~d}$ \\
Dm & $1.44 \pm 0.10 \mathrm{~b}$ & $1.30 \pm 0.08 \mathrm{a}$ & $2.13 \pm 0.08 \mathrm{c}$ & $2.09 \pm 0.12 \mathrm{c}$ & $2.36 \pm 0.10 \mathrm{~d}$ \\
M & $1.43 \pm 0.06 \mathrm{c}$ & $1.22 \pm 0.07 \mathrm{~b}$ & $1.13 \pm 0.05 \mathrm{a}$ & $1.15 \pm 0.07 \mathrm{a}$ & $1.42 \pm 0.16 \mathrm{c}$ \\
$\mathrm{bm}-\mathrm{cu}$ & $0.38 \pm 0.03 \mathrm{~b}$ & $0.35 \pm 0.02 \mathrm{a}$ & $0.40 \pm 0.02 \mathrm{c}$ & $0.40 \pm 0.04 \mathrm{c}$ & $0.50 \pm 0.03 \mathrm{~d}$ \\
r-m & $0.56 \pm 0.05 \mathrm{c}$ & $0.50 \pm 0.04 \mathrm{a}$ & $0.52 \pm 0.03 \mathrm{~b}$ & $0.49 \pm 0.04 \mathrm{a}$ & $0.53 \pm 0.03 \mathrm{~b}$ \\
dm-cu & $0.62 \pm 0.05 \mathrm{~b}$ & $0.58 \pm 0.04 \mathrm{a}$ & $0.70 \pm 0.03 \mathrm{c}$ & $0.70 \pm 0.05 \mathrm{c}$ & $0.86 \pm 0.03 \mathrm{~d}$ \\
\hline
\end{tabular}

Different letters in each row show significant different based on Tukey post hoc test (mean \pm SD).

Table 3. The angle degree and comparisons of vein measurements in different species Bactrocera spp.

\begin{tabular}{lrrrrr}
\hline Measurement & B. frauenfeldi & B. albistrigata & B. dorsalis & B. carambolae & B. cucurbitae \\
\hline Cell br & $38.81 \pm 2.18 \mathrm{a}$ & $40.81 \pm 2.12 \mathrm{a}$ & $58.14 \pm 3.16 \mathrm{~b}$ & $59.66 \pm 3.11 \mathrm{~b}$ & $71.02 \pm 2.10 \mathrm{c}$ \\
Cell dm & $58.62 \pm 2.12 \mathrm{a}$ & $61.56 \pm 3.04 \mathrm{a}$ & $93.66 \pm 2.64 \mathrm{c}$ & $89.64 \pm 2.90 \mathrm{c}$ & $87.51 \pm 2.40 \mathrm{c}$ \\
$\mathrm{Bm}: \mathrm{CuA} 1$ & $0.60 \pm 0.02 \mathrm{~b}$ & $0.56 \pm 0.02 \mathrm{~b}$ & $0.51 \pm 0.03 \mathrm{a}$ & $0.51 \pm 0.02 \mathrm{a}$ & $0.56 \pm 0.02 \mathrm{~b}$ \\
Dm : M & $0.98 \pm 0.05 \mathrm{a}$ & $0.98 \pm 0.05 \mathrm{a}$ & $1.90 \pm 0.07 \mathrm{~b}$ & $1.81 \pm 0.11 \mathrm{~b}$ & $1.71 \pm 0.08 \mathrm{~b}$ \\
Dm : CuA1 & $0.96 \pm 0.02 \mathrm{a}$ & $0.97 \pm 0.03 \mathrm{a}$ & $1.15 \pm 0.04 \mathrm{~b}$ & $1.15 \pm 0.03 \mathrm{~b}$ & $1.15 \pm 0.01 \mathrm{~b}$ \\
bm-cu : dm-cu & $0.60 \pm 0.03 \mathrm{a}$ & $0.61 \pm 0.03 \mathrm{a}$ & $0.58 \pm 0.04 \mathrm{a}$ & $0.56 \pm 0.03 \mathrm{a}$ & $0.58 \pm 0.02 \mathrm{a}$ \\
rm : dm-cu & $0.89 \pm 0.04 \mathrm{c}$ & $0.87 \pm 0.04 \mathrm{c}$ & $0.75 \pm 0.02 \mathrm{~b}$ & $0.70 \pm 0.03 \mathrm{~b}$ & $0.62 \pm 0.03 \mathrm{a}$ \\
\hline
\end{tabular}

Different letters in each row show significant different based on Tukey post hoc test (mean \pm SD). 
its discriminating power among Bactrocera species complexes studied. According to Adsavakulchai et al. (1999) that comparison of vein lengths provided an effective means for recognizing the different shapes. In addition, angle and ratio of the two different vein lengths can describe a shape of an object which is unaffected by changes in the position, the orientation, and the size of the object. (Mitteroecker et al., 2013). The previous geometric morphometric studies showed that wing shapes differ between taxonomic groups and can be used for insect identification (Henry et al., 2010; Schutze et al., 2012). In accordance with geometric morphometric, our finding is in line with the observations of Khamis et al. (2012) and Pieterse et al. (2017) who found that points in junction of vein $\mathrm{R} 4+5$ and $\mathrm{r}-\mathrm{m}$ crossvein and also junction of vein $\mathrm{M}$ and dm-cu influenced the landmark shifts in classifying Bactrocera and Ceratitis species. This present study provided conclusive evidence that clarified the differences of geometrical shapes in discriminating taxa for a quick diagnostic character of wing shape. Moreover, our result complemented previous diagnostic characters to categorize species complexes in the Genus Bactrocera. Initially, for classification purpose, the presence of a dark band in wing venation are classically used (Drew, 1989; Drew \& Romig, 2013).
Phylogenetic. The phylogenetic tree was generated according to Maximum-likelihood analysis with Tamura 3-parameter method (Tamura, 1992) and 1000x bootstrap repetition. Based on the highly sensitive comparison of nucleotide sequences in the mitochondrial genes, all species were essentially distinguishable and classified into a monophyletic group (Figure 3). The analysis revealed that the five Bactrocera species studied were separated into three major lineages, the first lineage was $B$. frauenfeldi complex consisting of $B$. frauenfeldi and $B$. albistrigata. Then, the second lineage was $B$. dorsalis complex consisting of $B$. dorsalis and $B$. carambolae, and the last lineage was $B$. cucurbitae. Two Bactrocera species both in the first and the second major lineages were considered as sibling species, which was supported by bootstrap analysis $>90 \%$ confidence level. This result also showed that B. cucurbitae had large genetic distance with both species complexes as it belonged to different Subgenus. The generated phylogenetic tree was in accordance with previous phylogenetic analysis of $C O I$ reported by Nakahara \& Muraji (2008), Boykin et al. (2014), and Jiang et al. (2014).

Our result was congruent with the evolutionary history shared by species studied. The morphometric approaches investigated in this research consistently

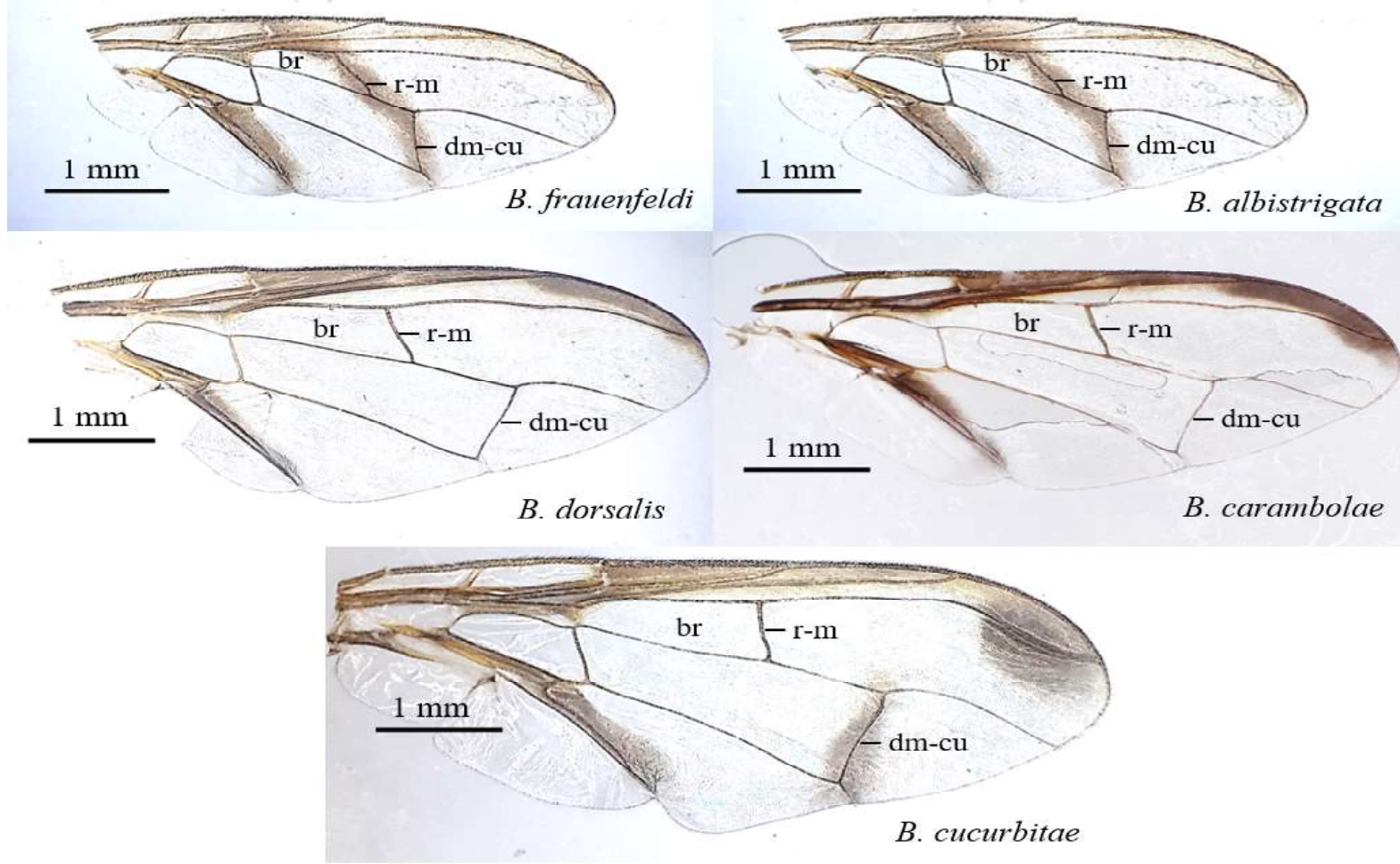

Figure 2. The wing venation of five species studied. 


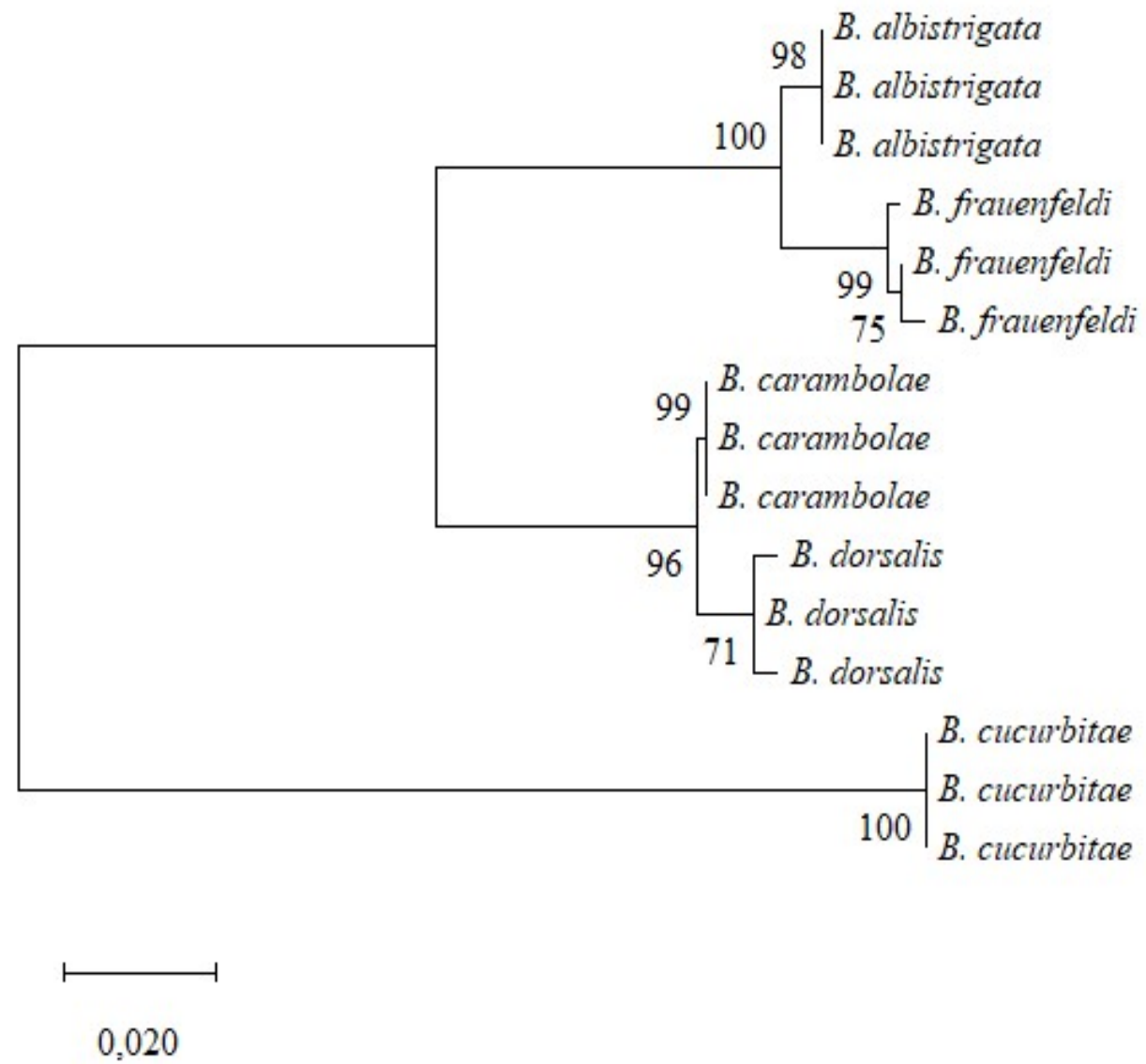

Figure 3. Phylogenetic tree generated by Maximum-likelihood analysis based on COI gene. Numbers at the nodes indicate bootstrap values.

explained the discriminating among species complexes studied as a phylogenetic tree. Perrard et al. (2014) confirmed that the genetic difference between wasp species had a stronger influence on the wing shape than other biotic or abiotic factors. Genetically, species complexes in genus Bactrocera are paraphyletic each other due to descent from different ancestral lines (Boykin et al., 2014; Krosch et al., 2020). However, the application of angle measure of cell br and ratio vein $r-m$ : dm-cu could demonstrate had a lack in showing the relationship between subgenus Bactrocera and Zeugodacus as phylogenetic tree showed. According to Drew (1989) subgenus Bactrocera can be distinguished from Zeugodacus based on the presence of lateral and medial vittae, where subgenus Bactrocera only has two lateral vittae but subgenus Zeugodacus has three vittae include medial vittae.

\section{CONCLUSION}

Based on this result, the degree angle of cell br and comparison between vein $\mathrm{r}-\mathrm{m}$ and $\mathrm{dm}-\mathrm{cu}$ is an appropriate tool for Bactrocera species complexes determination. For further study of these morphometric approaches, angle of cell br has advantage in a high degree ranges for clustering species complexes. To see its accuracy, these approaches must be tested with other species complexes, such as B. tryoni complex, B. tau complex, and B. xanthodes complex.

\section{ACKNOWLEDGMENTS}

The authors would like to thank the staffs from Sorong Quarantine, Laboratory of Vapor Heat Treatment BBPOPT, and Laboratory of Basic Entomology, Universitas Gadjah Mada for providing the equipment and chemicals required.

\section{REFERENCES}

Adsavakulchai A, Baimai V, Prachyabrued W, Grote PJ, \& Lertlum S. 1999. Morphometric study for identification of the Bactrocera dorsalis complex (Diptera: Tephritidae) using wing image analysis. Biotropia. 13: 37-48. 
Benítez HA. 2013. Assessment of patterns of fluctuating asymmetry and sexual dimorphism in carabid body shape. Neotrop. Entomol. 42(2): 164-169.

Boykin LM, Schutze MK, Krosch MN, Chomic A, Chapman TA, Englezou A, Armstrong KF, Clarke AR, Hailstones D, \& Cameron SL. 2014. Multigene phylogenetic analysis of south-east Asian pest members of the Bactrocera dorsalis species complex (Diptera: Tephritidae) does not support current taxonomy. J. Appl. Entomol. 138(4): 235-253.

Chown SL \& Gaston KJ. 2010. Body size variation in insects: a macroecological perspective. Biol. Rev. 85(1): 139-169.

Clarke AR. 2019. Biology and Management of Bactrocera and Related Fruit Flies. CABI Publishing. Boston.

Danjuma S, Thaochan N, Permkam S, \& Satasook C. 2014. Effect of temperature on the development and survival of immature stages of the carambola fruit fly, Bactrocera carambolae and the Asian papaya fruit fly, Bactrocera papayae, reared on guava diet. J. Insect. Sci. 14(1): 126.

Davidowitz G \& Nijhout HF. 2004. The physiological basis of reaction norms: the interaction among growth rate, the duration of growth and body size. Integr. Comp. Biol. 44(6): 443-449.

Doyle JJ \& Doyle JL.1990 Isolation of plant DNA from fresh tissue. Focus. 12(1): 13-15.

Drew RAI. 1989. The tropical fruit flies (Diptera: Tephritidae: Dacinae) of the Australasian and Oceanian Regions. Memoirs of the Queensland Museum, Queensland.

Drew RAI \& Romig MC. 2013. Tropical fruit flies (Tephritidae: Dacinae) of South-East Asia: Indomalaya to North-West Australasia. CABI, Wallingford.

Folmer O, Black M, Hoeh W, Lutz R, \& Vrijenhoek R. 1994. DNA primers for amplification of mitochondrial cytochrome $c$ oxidase subunit I from diverse metazoan invertebrates. Mol. Mar. Biol. Biotechnol. 3(5): 294-299.

Hall TA. 1999. BioEdit: a user-friendly biological sequence alignment editor and analysis program for Windows 95/98/NT. Nucleic Acids. Symp. Ser. 41: 95-98.
Henry A, Thongsripong P, Fonseca-Gonzalez I, JaramilloOcampo N, \& Dujardin JP. 2010. Wing shape of dengue vectors from around the world. Infect. Genet. Evol. 10(2): 207-214.

Iwahashi O. 1999a. Distinguishing between two sympatric species Bactrocera occipitalis and B. philippinensis (Diptera: Tephritidae), based on aedeagal length. Ann. Entomol. Soc. Am. 92(2): 182-187.

Iwahashi O. 1999b. Distinguishing between the two sympatric species Bactrocera carambolae and B. papayae (Diptera: Tephritidae) based on aedeagal length. Ann. Entomol. Soc. Am. 92(5): 639-643.

Iwahashi O. 2001. Aedeagal length of the oriental fruit fly, Bactrocera dorsalis (Hendel) (Diptera: Tephritidae), and its sympatric species in Thailand and the evolution of a longer and shorter aedeagus in the parapatric species of B. dorsalis. Appl. Entomol. Zool. 36(3): 289-297.

Jiang F, Jin Q, Liang L, Zhang AB, \& Li ZH. 2014. Existence of species complex largely reduced barcoding success for invasive species of Tephritidae: a case study in Bactrocera spp. Mol. Ecol. Resour. 14(6): 1114-1128.

Khamis FM, Masiga DK, Mohamed SA, Salifu D, de Meyer M, \& Ekesi S. 2012. Taxonomic identity of the invasive fruit fly pest, Bactrocera invadens: concordance in morphometry and DNA barcoding. PLoS ONE. 7(9): e44862.

Kitthawee S \& Dujardin JP. 2010. The geometric approach to explore the Bactrocera tau complex (Diptera: Tephritidae) in Thailand. Zoology. 113(4): 243-249.

Kitthawee S \& Rungsri N. 2011. Differentiation in wing shape in the Bactrocera tau (Walker) complex on a single fruit species of Thailand. Scienceasia. 37(4): 308-313.

Krosch MN, Schutze MK, Armstrong KF, Boontop Y, Boykin LM, Chapman TA, Englezou A, Cameron SL, \& Clarke AR. 2013. Piecing together an integrative taxonomic puzzle: microsatellite, wing shape and aedeagus length analyses of Bactrocera dorsalis s.l. (Diptera: Tephritidae) find no evidence of multiple lineages in a proposed contact zone along the Thai/Malay Peninsula. Syst. Entomol. 38(1): 2-13. 
Krosch MN, Strutt F, Blacket MJ, Batovska J, Starkie M, Clarke AR, Cameron SL, \& Schutze MK. 2020. Development of internal COI primers to improve and extend barcoding of fruit flies (Diptera: Tephritidae: Dacini). Insect Sci.27(1): 143-158.

Kumar S, Stecher G, Li M, Knyaz C, \& Tamura K. 2018. MEGA X: molecular evolutionary genetics analysis across computing platforms. Mol. Biol. Evol. 35(6): 1547-1549.

Leblanc L, Hossain MA, Khan SA, Jose MS, \& Rubinoff D. 2013. A preliminary survey of the fruit flies (Diptera: Tephritidae: Dacinae) of Bangladesh. Proceedings of the Hawaiian Entomological Society. 45: 51-58.

Marsteller S, Adams DC, Collyer ML, \& Condon M. 2009. Six cryptic species on a single species of host plant: morphometric evidence for possible reproductive character displacement. Ecol. Entomol. 34(1): 66-73.

Mitteroecker P \& Gunz P. 2009. Advances in geometric morphometrics. Evol. Biol. 36(2): 235-247.

Mitteroecker P, Gunz P, Windhager S, \& Schaefer K. 2013. A brief review of shape, form, and allometry in geometric morphometrics, with applications to human facial morphology. Hystrix. 24(1): 59-66.

Nakahara S \& Muraji M. 2008. Phylogenetic analysis of Bactrocera fruit flies (Diptera: Tephritidae) based on nucleotide sequences of the mitochondrial COI and COII genes. Res. Bull. Pl. Prot. Japan. 44: 1-12.

Perrard A, Baylac M, Carpenter JM, \& Villemant C. 2014. Evolution of wing shape in hornets: why is the wing venation efficient for species identification?.J. Evol. Biol. 27(12): 2665-2675.

Perre P, Jorge LR, Lewinsohn TM, \& Zucchi RA. 2014. Morphometric differentiation of fruit fly pest species of the Anastrepha fraterculus group (Diptera: Tephritidae). Ann. Entomol. Soc. Am. 107(2): 490-495.

Pieterse W, Benítez HA, \& Addison P. 2017. The use of geometric morphometric analysis to illustrate the shape change induced by different fruit hosts on the wing shape of Bactrocera dorsalis \& Ceratitis capitata (Diptera: Tephritidae). Zool. Anz. 269: 110-116.
Sentinella AT, Crean AJ, \& Bonduriansky R. 2013. Dietary protein mediates atrade-off between larval survival and the development of male secondary sexual traits. Funct. Ecol.27(5): 1134 1144.

Schutze MK, Jessup A, \& Clarke AR. 2012. Wing shape as a potential discriminator of morphologically similar pest taxa within the Bactrocera dorsalis species complex (Diptera: Tephritidae). Bull. Entomol. Res. 102(1): 103-111.

Schutze MK, Jessup A, U1-Haq I, Vreysen MJB, Wornoayporn V, Vera MT, \& Clarke AR. 2013. Mating compatibility among four pest members of the Bactrocera dorsalis fruit fly species complex (Diptera: Tephritidae). J. Econ. Entomol. 106(2): 695-707.

Soto IM, Soto EM, Corio C, Carreira VP, Manfrin M, \& Hasson E. 2010. Male genital and wing morphology in the cactophilic sibling species Drosophila gouveai and Drosophila antonietae and their hybrids reared in different hostplants. Environ. Entomol. 39(3): 865-873.

Tamura K. 1992. Estimation of the number of nucleotide substitutions when there are strong transitiontransversion and $\mathrm{G}+\mathrm{C}$-content biases. Mol. Biol. Evol. 9(4): 678-687.

Tan KH, Tokushima I, Ono H, \& Nishida R. 2011. Comparison of phenylpropanoid volatiles in male rectal pheromone gland after methyl eugenol consumptions, and molecular phylogenetic relationship of four global pest fruit fly species: Bactrocera invadens, $B$. dorsalis, $B$. correcta and B. zonata. Chemoecology. 21(1): 25-33.

Wee SL \& Tan KH. 2005. Evidence of natural hybridization between two sympatric sibling species of Bactrocera dorsalis complex based on pheromone analysis. J. Chem. Ecol. 31(4): $845-858$.

Zaelor J \& Kitthawee S. 2018. Geometric morphometric and molecular evidence suggest a new fruit fly species in Bactrocera zeugodacus tau complex Diptera: Tephritidae. Zoological Systematics. 43(1): 27-36. 